\section{Functional Assessment}

Sue Ann Sisto

School of Health Technology and Management Stony Brook University, Stony Brook, NY, USA

\section{Definition}

Functional assessment encompasses the measurement of medical, physical, and mental health. Through functional assessments, clinicians develop an understanding of an individual's condition and activities and how they use critical skills to be successful and satisfied in their environment. Functional assessment is a decision process that results from the interaction between classifications such as diagnosis and measures. It aims to recognize, anticipate, or modify the interaction between the disabled person and his or her environment using measures of such factors as independence, pain, cognitive capacity, or fatigability. Functional assessments have become a cornerstone of rehabilitation medicine, assisting in well-defined aims such as quality assurance, continuous quality improvement, accountability, cost-benefit analysis, education, and research.

\section{References and Readings}

Ring, H. (2007). Functional assessment in rehabilitation medicine: Clinical applications. Europa Medicophysica, 43(4), 515-523.

Tesio, L. (2007). Functional assessment in rehabilitative medicine: Principles and methods. Europa Medicophysica, 43(4), 551-556. 